\title{
MUDANÇAS CLIMÁTICAS E AS FORMAS DE OCUPAÇÃO URBANA: PROCESSO DE CRIAÇÃO DE CENÁRIOS SOCIOAMBIENTAIS
}

\author{
CLIMATE CHANGES AND THE URBAN FORM: \\ THE PROCESS OF DEVELOPING SOCIOENVIRONMENTAL SCENARIOS
}

Laura Machado de Mello Bueno

Doutora, Professora do PosUrb da PUC-Campinas - CEATEC

email: laurab@puc-campinas.edu.br

Vera Regina Tangari

Doutora, Professora do ProArq-UFRJ

email:vtangari@uol.com.br;

Jonathas Magalhães Pereira Silva

Doutor, Professor do PosUrb da PUC-Campinas - CEATEC

email: jonathas.silva@puc-campinas.edu.br;

Cláudia Cotrim Pezzuto

Doutora, Professora da PUC-Campinas - CEATEC

email: claudiapezzuto@puc-campinas.edu.br;

Rita de Cássia Martins Montezuma

Doutora, Professora da PUC-Rio

email: montezum@puc-rio.br;

Andrea de Queiroz Rego

Doutora, Professora do ProArq-UFRJ

email: aqrego@yahoo.com.br.

\section{RESUMO}

Este artigo é fruto de reflexões desenvolvidas a partir de encontros entre pesquisadores vinculados ao PROARQ-FAU/UFRJ, ao Departamento de Geografia da PUC-Rio e ao Mestrado em Urbanismo da PUC Campinas, integrado ao Centro de Ciências Exatas, Ambientais e de Tecnologias - CEATEC. Por meio das pesquisas produzidas isoladamente por estas instituições, buscou-se, após um intenso trabalho de diálogo entre os pesquisadores, elaborar um método para novas investigações. Ele foi construído a partir das argumentações teóricas que levaram o grupo a uma busca pela integração de pesquisas de diferentes áreas e subáreas do conhecimento, concretizando-se em um projeto de pesquisa interinstitucional. Agora inicia-se a realização dessas pesquisas, com apoio da FAPESP e FAPERJ, que terão dois anos de duração. As investigações estão voltadas para espaços urbanos e periurbanos em suas dimensões socioambientais relacionadas a: comportamento de variáveis climáticas nos espaços urbanos consolidados; avaliação da qualidade da cobertura vegetal nas florestas contíguas a áreas urbanizadas; avaliação de intervenções em áreas de alta vulnerabilidade; localização dos investimentos públicos em habitação e infraestrutura em espaços não 
edificados; dinâmica das águas urbanas e sua relação com o uso e ocupação do solo e legislação urbanística. $\bigcirc$ artigo discute as bases teóricas e propõe questões metodológicas aplicáveis a estudos comparativos para a realização de cenários futuros visando a adaptação dos espaços urbanos e periurbanos a mudanças climáticas em curso. $\bigcirc$ intercâmbio entre os pesquisadores permitiu um primeiro avanço tendo como resultado a construção de um método aqui apresentado. $\bigcirc$ objetivo do artigo é a apresentação da metodologia para ampliação do debate referente às questões teóricas e metodológicas envolvidas.

Palavras-chave: Mudanças climáticas, Clima urbano, Uso e ocupação do solo urbano, Indicadores socioambientais, Parâmetros urbanísticos

\begin{abstract}
This article is based on ideas developed from meetings hold by researchers linked to PROARQ-FAU/ UFRJ, Department of Geography at PUC-Rio and Master of Urban Design, PUC Campinas, integrated to the Center for Science, Technology and Environment - CEATEC. Through the research made by these institutions we present in this text, after an intense dialogue, the method built up from the theoretical arguments that led the group seek the integration of the studies developed in different fields and subfields of knowledge. An interinstitutional research, has been undertaken from 2011 until 2013, with support of the agencies of São Paulo and Rio de Janeiro provinces. The ideas discussed here are focused on urban and peri-urban areas and their social and environmental dimensions related to: climate variables in consolidated urban areas; evaluation of the vegetation quality in forests adjacent to urban areas; evaluation of urban interventions in areas of high vulnerability; public investment allocation in housing and infrastructure projects; urban water dynamics and its relation to land use and occupation and to urban legislation. The article discusses the theoretical and methodological issues relevant to propose comparative studies for the realization of future scenarios in order to adapt the urban and peri-urban climate changes in progress. The exchange among the researchers has allowed a first progress resulting in the construction of the method presented. The aim of this paper is to expand the debate concerning the theoretical and methodological issues involved.
\end{abstract}

Keywords: Climate change, Urban climate, Use and occupation of urban land, Social and environmental parameters

\title{
1. INTRODUÇÃO
}

Este artigo é fruto do esforço de integrar pesquisas de diferentes áreas de conhecimento, voltadas para os espaços urbanos e periurbanos, para desenvolver prospecções sobre o futuro dos assentamentos humanos com maior justiça socioambiental. Parte de estudos já existentes sobre territórios nos quais há grandes desigualdades nas condições de conforto e acesso a serviços urbanos, em uma conjuntura de mudanças climáticas globais. Foram adotados diferentes recortes territoriais visando representar as principais tipologias de ocupação. Como recorte territorial principal optou-se pelas regiões metropolitanas de Campinas (RMC) e Rio de Janeiro (RMRJ) por terem sido objeto de investigação dos autores do presente texto. Além destes, foi incluído o município de Friburgo/RJ, por estar sob a influência indireta da RMRJ. Os estudos relacionados, elaborados por pesquisadores das equipes, abarcam: a localização dos investimentos recentes em habitação e infraestrutura (SILVA, 2011; BUENO et al., 2009) e sua interface nos sistemas de espaços não edificados (SILVA, 2010; TANGARI, SCHLEE e ANDRADE, 2009); a legislação urbanística vigente (SCHLEE e TANGARI, 2008 e 2009; BUENO e CYMBALISTA, 2007; SILVA, 2011, 2010b); a avaliação de intervenções em áreas 
de alta vulnerabilidade (OLIVEIRA e BUENO, 2009); a dinâmica das águas urbanas e sua relação com o uso e ocupação do solo (BUENO, 2008; BUENO e MARTINS, 2007; TANGARI, SCHLEE e ANDRADE, 2005; TANGARI, SCHLEE, ANDRADE e DIAS, 2007; TÂNGARI, DIAS e AMORIM, 2007; SILVA, 2007); o comportamento de variáveis climáticas nos espaços urbanos consolidados (PEZZUTO, LABAKI e FRANCISCO FILHO, 2008; DACANAL, PEZZUTO e LABAKI, 2008; e, PEZZUTO, 2007); e avaliação da qualidade da cobertura vegetal nas florestas contíguas (MONTEZUMA, 2005; SANTOS, MONTEZUMA e MARANHÃO, 2009; MONTEZUMA e OLIVEIRA, 2010; e, MONTEZUMA e SESANA, 2010).

As políticas públicas relacionadas ao meio urbano pouco têm considerado a problemática ambiental, em especial as novas demandas associadas ao risco de efeitos das mudanças climáticas globais (BUENO, 2008, 2010) e locais. Os estudos climáticos consideram as diferentes escalas, considerando-se os espaços urbanos como clima local e microclima (ANDRADE, 2005). Esses não teriam necessariamente relação direta com efeitos climáticos globais. Porém, a literatura recente já relaciona impactos entre condições de segurança e conforto urbanos e os efeitos de mudanças climáticas globais em curso. Esse fenômeno fica mais perceptível em grandes aglomerados urbanos como as metrópoles, nas quais os efeitos entre o mesoclima e o microclima devem ser considerados. Segundo Nobre et al. (2010), no caso da Região Metropolitana de São Paulo, há uma previsão de duplicação do número de dias com chuvas intensas, entre 2070 e 2100 , e, a mais curto e médio prazos, o aumento do número de dias quentes, diminuição do número de dias frios, aumento de noites quentes e diminuição do número de noites frias. Prevê-se, também, uma intensificação da ilha de calor, com prejuízo da dispersão de polventes atmosféricos. Hunt e Watkiss (2010) fazem uma revisão abrangente da literatura mundial sobre grandes cidades e mudanças climáticas. Mostram que a maior parte dos estudos avalia a dinâmica da vulnerabilidade e das situações e populações em risco. Há pouquíssimos estudos prospectivos com vistas à adaptação dos espaços urbanos.

As diversas condições adversas ao conforto e à segurança humana nos assentamentos urbanos em grande parte das cidades brasileiras, em especial nas metrópoles, devem se agravar em decorrência de mudanças climáticas globais e locais. São previstas repercussões como o aumento da vulnerabilidade do espaço construído e de seus usuários, do custo de manutenção e adaptação da infraestrutura, dos espaços urbanos e das edificações, com efeitos socioeconômicos de diversas ordens, desde a perda de vidas humanas ao aumento do custo dos seguros dos bens localizados em determinadas parcelas das áreas urbanas (HOAF, 2009).

Na legislação urbanística, na gestão urbana e nos processos socioeconômicos de urbanização, não se tem computado os problemas socioambientais e as mudanças climáticas. A ação do poder público na implantação de sistemas de mobilidade, infraestrutura urbana e equipamentos é geralmente morosa e incompleta, com a ocorrência de solos expostos e instabilizados, comprometimento da dinâmica hidrológica e adensamentos populacionais desprovidos de serviços. Os modelos de desenvolvimento urbano formais 
(verticalização, alta impermeabilização do solo, preponderância de áreas com alta amplitude térmica, tendência ao uso de iluminação e climatização artificial) e informais (solos expostos e instáveis devido à infiltração de água residuais, infraestrutura e edificações frágeis) aumentam o risco de impactos negativos relacionados às consequências de eventos climáticos extremos nas cidades, bem como sua maior dependência de insumos externos e distantes (energia, água, materiais de construção e abastecimento de forma geral). $\bigcirc$ planejamento territorial urbano e periurbano, de forma geral não se baseiam em condicionantes topográficos, geomorfológicos e geoecossistêmicos na definição do uso e ocupação do solo futuro, bem como nas características de desempenho das edificações. $\bigcirc$ estudo dos fundos de vale e encostas torna-se de grande importância, pois, além de seu papel na dinâmica das águas urbanas, influencia nas condições dos fluxos hídricos, cobertura vegetal e estabilidade do solo (dado que o aumento da energia de escoamento altera o poder destrutivo da água pelo aumento do arraste) e oferece oportunidades de circulação do ar, resfriamento e dissipação de polventes. A associação das características geomorfológicas e as tipologias vegetacionais definem e regulam os processos hidrológicos que afetam as encostas e planícies, que, em resposta aos regimes climáticos, são remodeladas por movimentos de massa ou perdas erosivas (MONTEZUMA, 2005).

No caso de áreas metropolitanas, não há mecanismos institucionais que garantam a elaboração de planos territoriais integrados, mesmo em situações de conurbação, de bacias hidrográficas e fragmentos vegetais contínuos. Os Planos Diretores, elaborados a partir da Lei Federal do Estatuto das Cidades, são de abrangência municipal e pouco responderam à problemática atual, tendo, em muitas situações, apenas consagrado a concentração de investimentos públicos e privados nos mesmos moldes urbanísticos, morfológicos e tecnológicos (PINTO, 2006). Na sua regulamentação são utilizados modelos urbanísticos e processos de produção nocivos, tais como: a expansão urbana através do parcelamento e infraestrutura paulatina, com construção de unidades individualizadas ou conjuntos habitacionais desprovidos de integração urbanística; a verticalização em áreas consolidadas; a ampliação do sistema viário sobre áreas frágeis, em especial, fundos de vale, encostas, áreas alagadas e alagáveis. A falta de um setor público eficaz e equipado no controle do uso e ocupação do solo urbano compromete ainda mais o espaço urbano, pois são aplicados modelos urbanísticos que não correspondem mais às características de vulnerabilidade do ambiente construído. A implementação recente de bases institucionais, legais e políticas mais abrangentes, como a criação do Ministério das Cidades e a aprovação de diversas legislações relacionadas à habitação e saneamento, baseadas na compreensão do passivo urbanístico e social, não reflete uma cultura de planejamento futuro, que considerasse, além dos problemas herdados, a dinâmica socioambiental recente e as prospecções de mais longo prazo relacionadas às mudanças climáticas (BUENO, 2010). A falta de preparação dos espaços urbanos para essas novas situações poderá levar a uma deterioração crescente das cidades, com perda dos investimentos públicos e privados, desvalorização de patrimônio imobiliário, ampliação de reformas urgentes, além das perdas de vidas humanas. 


\section{OBJETIVO}

Esse artigo tem como objetivo compartilhar os resultados de um processo coletivo e interinstitucional de aprimoramento de metodologias de pesquisa sobre o ambiente construído.

Essa experiência resultou em uma metodologia que será aplicada em uma pesquisa que tem como objetivo principal contribuir para a implementação de processos de adaptação dos espaços urbanos ao contexto das paisagens em que estão inseridos, visando a mitigação de impactos resultantes das mudanças climáticas. A pesquisa, denominada "Mudanças Climáticas e as Formas de Ocupação Urbana: Estudos comparativos de tipos de ocupação e indicadores socioambientais para adaptação de situações de vulnerabilidade e risco das regiões metropolitanas de Rio de Janeiro e Campinas", recebeu apoio da FAPESP e da FAPERJ' e terá duração de dois anos. Serão realizadas pesquisas empíricas em áreas selecionadas do Rio de Janeiro e São Paulo, com a mesma metodologia, que será aprimorada através da troca de experiências entre as equipes de cada local.

A pesquisa tem como objetivos específicos:

- indicar a relação entre parâmetros socioambientais (urbanísticos), físico ambientais (geoecológicos) e de conforto no uso dos espaços urbanos, no caso das novas situações climáticas associadas às mudanças climáticas;

- gerar novas concepções de formulação da legislação urbanística e de planos urbanos que considerem os condicionantes climáticos (de conforto e de risco);

- resultar no aprimoramento dos pesquisadores e alunos, em inovações no ensino e pesquisa na área de Geografia, Ecologia Urbana, Arquitetura e Urbanismo, com a incorporação de metodologias de elaboração de cenários tridimensionais conforme aspectos socioambientais (urbanísticos), físico ambientais (geoecológicos) e de conforto e clima associados.

\section{MÉTODO (PARA CHEGAR AO MÉTODO)}

A originalidade do método construído reside na oportunidade de integrar simultaneamente parâmetros geobiofísicos, socioambientais e urbanísticos. A transdisciplinaridade possibilita a geração de modelos de planejamento urbano integrados a um diagnóstico das condições físicas e sociais, que constituem o espaço urbano, através de análises multiescalares dos processos ambientais. A contribuição de cada pesquisador no conhecimento disciplinar, nos questionamentos, proporcionou a estruturação de passos metodológicos que se adequam a cada enfoque escalar e disciplinar. A localização das áreas de estudos é representativa das principais condições geográficas mais vulneráveis aos eventos extremos, associados às mudanças climáticas, uma vez que apresentam diferentes atributos, variados e conjugados em diferentes formas, comportando compartimentos do relevo plano, montanhoso, florestal, rural, urbano e em diferentes graus de desenvolvimento, em alguns casos, na mesma bacia hidrográfica. Essa heterogeneidade 
de áreas e condições corrobora o desenvolvimento de cenários mais abrangentes, ampliando a capacidade de modelos que promoverão o aprimoramento do método desenvolvido até o presente momento que envolve:

- delimitação de unidades espaciais de interesse para o planejamento de ações visando à diminuição de vulnerabilidades e a adaptação do meio urbano, partindo da delimitação de bacias hidrográficas;

- estudo das encostas, dos fundos de vale e baixadas, no meio urbano, sob o aspecto socioambiental e físico ambiental com foco no aspecto climático;

- percepção do impacto dos grandes projetos, financiados pelo Programa de Aceleração do Crescimento (PAC) na: gestão do solo urbano, evolução da ocupação, manutenção das condições da cobertura vegetal das florestas urbanas;

- identificação dos principais processos e funções ecossistêmicas de florestas urbanas;

- acompanhamento da crescente transformação do padrão de uso do solo de ambiente rural para urbanizado;

- localização dos investimentos públicos recentes e na legislação urbana atual, verificando processo de intensificação ou não da vulnerabilidade;

- elaboração de cenários e de avaliação de paisagens e espaços urbanos com vista a sua adaptação a mudanças climáticas;

- reavaliação metodológica a partir dos resultados em cada etapa nas duas regiões.

\section{ANÁlisE DE RESULTADOS}

Os resultados obtidos, a partir da experiência de uma avaliação mais transversal dos processos ambientais, permitiram a construção de uma estratégia de ação, que passa a ser aqui detalhada para que seja possível ampliar o debate com outras instituições e pesquisadores interessados na abordagem aqui construída. $\bigcirc$ processo foi iniciado através de discussões presenciais e remotas, leituras e discussão de papers dos pesquisadores. E deverá ser alimentado continuamente, com a realização de atividades de campo conjuntas e trocas periódicas de resultados parciais.

Após uma primeira aproximação foram definidos os recortes territoriais macro e mesoescalares - as áreas metropolitanas do Rio de Janeiro e de Campinas, SP, abrangendo contextos geomorfológicos e funcionais de interesse para os estudos sobre vulnerabilidade e adaptação. No caso da RMC devem-se estudar as dinâmicas do contexto das bacias hidrográficas. No caso do Rio de Janeiro serão estudadas as relações com a região serrana.

Partiu-se, então, para a seleção de áreas para levantamentos de campo específicos, potencializando a interpretação de imagens de satélite e um aprofundamento analítico das pesquisas realizadas anteriormente.

Para levantamento de indicadores socioambientais e climáticos definimos três recortes selecionados em cada estado.

Na RMC tomou-se a área estudada por Pezzuto, em 2007, de forma a realizar-se uma atualização e comparação com os resultados daquela pesquisa, inserindo outros 


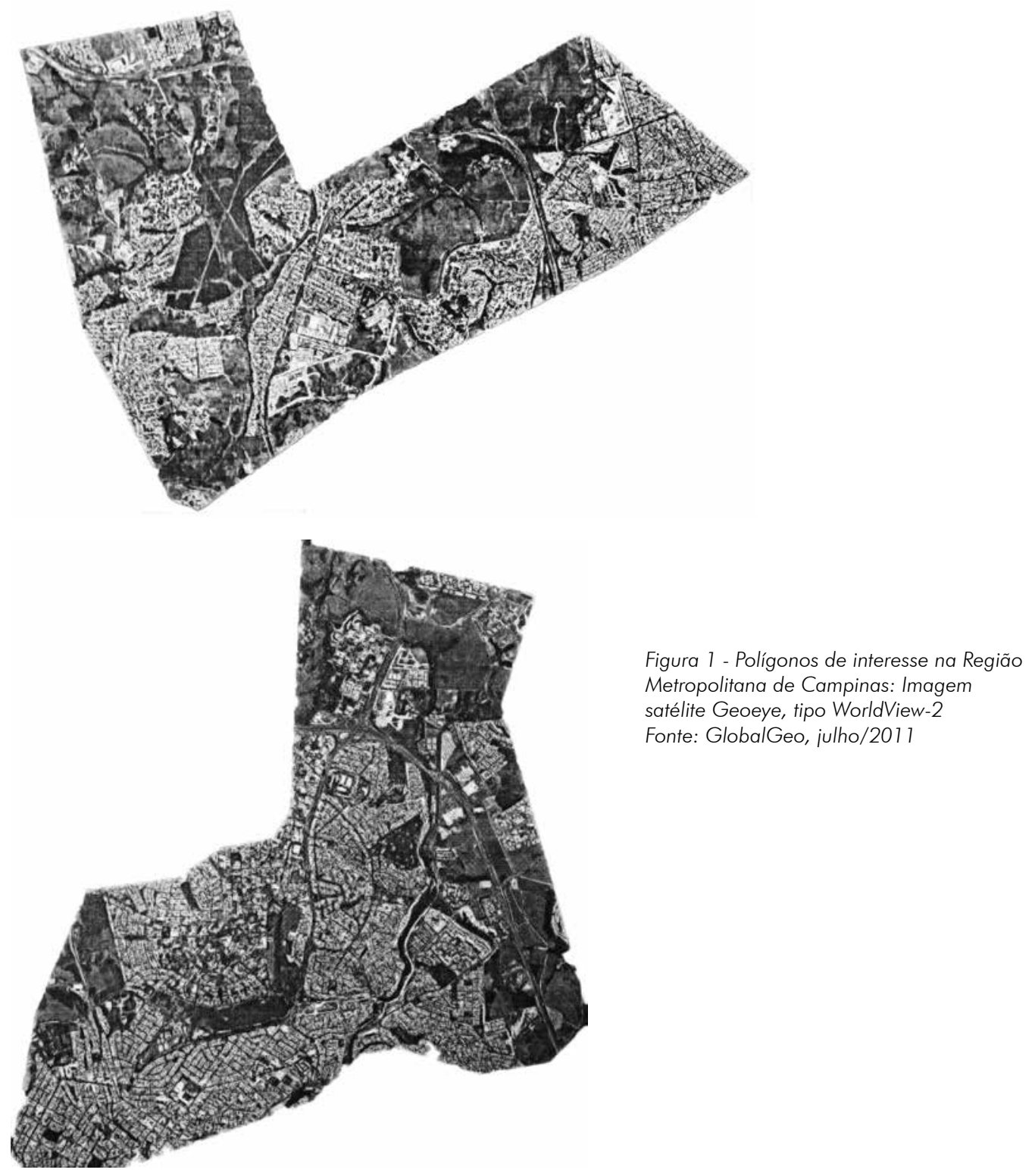

elementos de importância na dinâmica climática. Trata-se de área central da região metropolitana parcialmente verticalizada, com intensa impermeabilização, no município de Campinas. Encontra-se na bacia hidrográfica do rio Atibaia, sub-bacia do ribeirão Anhumas. Serão selecionadas mais duas áreas fora da área urbana consolidada da metrópole, uma área urbana com intensa modificação do uso do solo. Recentes mudanças na legislação dos municípios têm viabilizado a urbanização de terras rurais, tanto a norte/noroeste (bacias hidrográficas do ribeirão Quilombo, um dos mais importantes receptores de dejetos urbano-industriais, e do rio Atibaia) quanto a sul/sudoeste (bacia hidrográfica do rio Capivari). Além dos empreendimentos públicos em andamento (Programa MCMV e obras de ampliação do Aeroporto Viracopos), prevê-se a implantação do trem de alta velocidade ligando São Paulo ao Rio de Janeiro. 
No Rio de Janeiro foram selecionadas duas áreas na Região Metropolitana (Rio de Janeiro, Magé e Guapimirim) e uma área de influência indireta (Nova Friburgo). No município do Rio de Janeiro, selecionou-se uma área de expansão urbana, situada na zona oeste, mas especificamente na área conhecida como Vargens, a qual compreende os bairros do Camorim, Vargem Grande e Pequena, onde está incluída parte do Parque Estadual da Pedra Branca, com recente mudança na legislação urbanística e forte pressão do mercado imobiliário, devido à influência de investimentos relacionados às Olimpíadas de 2016. No segundo recorte, nos municípios de Magé e Guapimirim, nosso interesse é aplicar o método de simulação dos cenários em outra pesquisa em andamento, sobre a influência da implantação do Arco Rodoviário Metropolitano na paisagem e nos sistemas de espaços livres. $\bigcirc$ interesse do estudo em Nova Friburgo será o de elaborar cenários em município de influência indireta da Região Metropolitana e do empreendimento do Complexo Petroquímico da Petrobrás-COMPERJ, em Itaboraí. Nesse caso, além de também já ter sido objeto de pesquisa anterior já finalizada (REGO et al., 2009), a área foi recentemente atingida por eventos climáticos extremos, sendo sua análise integrada à pesquisa de Vulnerabilidade Florestal.

A experiência nos mostrou que a abordagem adotada aproximou pesquisadores de diversas instituições, localidades e realidades na análise de problemas comuns, o que propicia a formação de um método sob um novo paradigma, possibilitando, desde o início, a vivência da realização de pesquisas integradas, multiescalares e multidisciplinares.

A interdisciplinaridade permite estabelecer melhores bases conceituais polissêmicas, ajustar determinados procedimentos e métodos e dar clareza a algumas definições

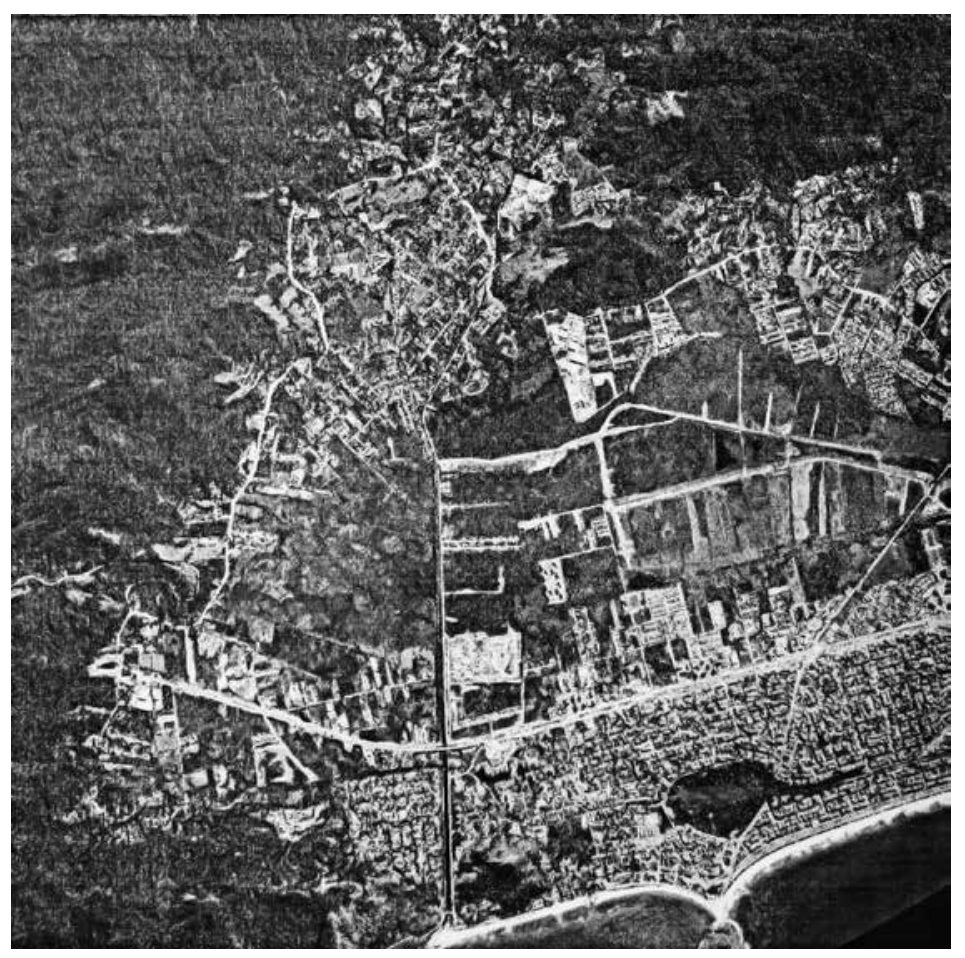

Figura 2 - Polígonos de interesse na área metropolitana do Rio de Janeiro - Imagem Satélite Geoeye, Tipo WorldView-2 Fonte: GlobalGeo, julho/2011 
insuficientemente fundamentadas, tais como risco, vulnerabilidade, adaptação e sustentabilidades. Percebeu-se a necessidade da produção de um glossário que esclareça ou estabeleça as fronteiras entre essas diversas bases conceituais.

A metodologia proposta integra diferentes métodos e ferramentas analíticas das áreas de conhecimento envolvidas, para interpretação dos processos de produção do espaço urbano e de elaboração de hipóteses de sua adaptação. Fundamenta-se: no levantamento de indicadores socioambientais (dentre os quais os urbanísticos), socioeconômicos e físico ambientais; na sua avaliação através do uso do geoprocessamento como ferramenta de apoio à tomada de decisão no processo de planejamento; e na elaboração de cenários futuros através da simulação computacional, cotejando a dinâmica urbana com a climática.

Construímos, coletivamente, o método de pesquisa, com cinco etapas, representado na Figura 3, na qual (In.) representa a atividade contínua de troca entre as equipes, os intercâmbios.

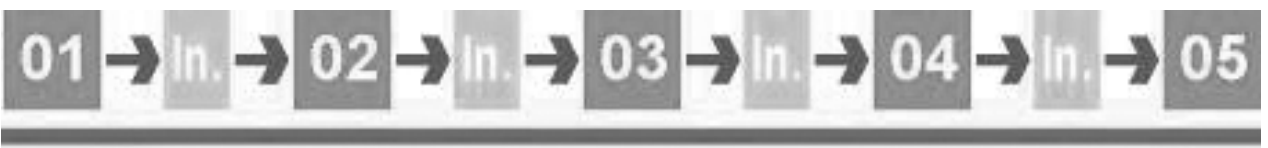

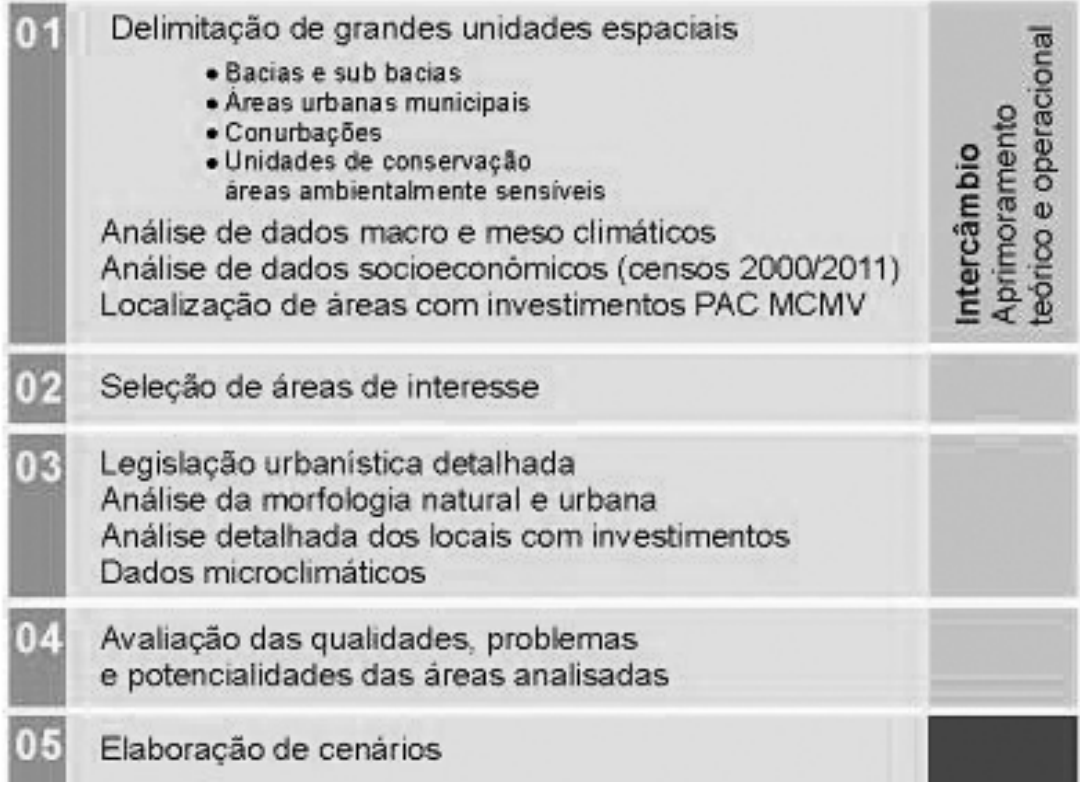

Figura 3 - Metodologia da pesquisa.

Fonte: Gráfico elaborado pelos autores

O Intercâmbio corresponde às atividades de embasamento teórico e treinamento, entre os diferentes saberes e contextos específicos, a partir da atividade da pesquisa empírica. Os levantamentos de campo nas áreas - urbana e rural/florestal - são acompanhados pelos pesquisadores e alunos das instituições envolvidas para conhecimento sobre as especificidades metodológicas decorrentes, através das missões de intercâm- 
bio. As equipes recebem treinamento para trabalho de campo e uso de software de georreferenciamento para processamento e cruzamentos dos dados. Tem um caráter de continuidade, que perpassa as demais etapas.

A Ełapa 1 consiste na sistematização de estudos em macroescala. Prevê-se a elaboração de bases cartográficas gerais, fundamental para consolidar a sistematização analítica dos dados conforme os objetivos de análises espaciais tridimensionais. A análise destes contextos territoriais e sua discussão resultarão no passo seguinte.

A Ełapa 2 consiste na seleção de áreas de estudo para levantamentos sobre uso e ocupação do solo, cobertura vegetal e indicadores urbanísticos, climáticos e geoecológicos. Serão estudados, também, os dados dos censos demográficos de 2000 e 2010, para caracterização socioeconômica das áreas e das densidades populacionais e habitacionais. Pretende-se estudar três áreas em diferentes contextos urbanos e periurbanos, em cada região metropolitana, incluindo-se locais nos quais estejam ou tenham sido realizados investimentos públicos recentes. Mas a primeira delas, em cada um dos estados, já está definida, pois foi objeto de pesquisas anteriores. Nosso interesse é usar resultados de outras pesquisas realizadas, para a definição da primeira área, e desta forma poder efetuar, com base nos dados já produzidos, os estudos de simulação de cenários sobre o clima urbano, parâmetros urbanísticos, assim como conjugar esses cenários à avaliação de produtividade florestal, testando desta forma as inovações metodológicas propostas, logo no primeiro ano da pesquisa. Serão também selecionadas, após a realização da Ełapa 3 na primeira área.

As etapas 3, 4 e 5 serão realizadas para cada área selecionada.

Na Ełapa 3 serão realizados, nas áreas do Rio de Janeiro, os levantamentos de indicadores físico ambientais a fim de avaliar os mecanismos de transformação da paisagem, que contemplam a substituição das florestas por outros tipos de cobertura e a resposta dos remanescentes florestais frente às transformações. Na metrópole campineira serão levantados indicadores sobre clima urbano e morfologia de fundos de vale urbanos. Serão levantados e analisados, detalhadamente, a legislação urbanística e as características morfológicas dos processos de urbanização destas áreas. Os dados climáticos e urbanísticos servirão para calibrar o programa ENVI-MET, que será usado na etapa seguinte.

Na Etapa 4 pretende-se selecionar polígonos, com aproximadamente $500 \times 500$ metros, dentro das áreas delimitadas previamente. Essa área se encontra no limite recomendável para a simulação computacional através do programa ENVI-MET. Estas áreas serão então monitoradas com sensores de temperatura e umidade relativa do ar. Dessa forma, para cada uma das três áreas serão feitas avaliações relacionando os resultados sobre as características urbanas de uso e ocupação, demográficas, comportamento climático e, nas áreas periurbanas, também o florestal.

Na Ełapa 5 serão elaboradas hipóteses, relacionando diferentes processos socioespaciais que resultem em cenários alternativos, nos quais serão cotejados os resultados de dados climáticos com diferentes usos e formas de ocupação do solo, com parâmetros urbanísticos e ambientais relacionados. 
Para este estudo utiliza-se o programa ArcGis, o qual apresenta um conjunto de ferramentas capaz de gerenciar, explorar e armazenar dados georreferenciados. Neste momento, através do uso do geoprocessamento, é possível realizar o cruzamento de todos os indicadores urbanos coletados, imagens de satélites, dados do IBGE, dados ambientais, entre outros, com o objetivo de subsidiar o planejamento urbano. Para a elaboração dos cenários futuros, visando averiguar os impactos positivos e negativos de morfologias urbanas e o conforto em situações de mudanças climáticas, propõe-se elaborar hipóteses de variação de parâmetros climáticos baseadas nos levantamentos, executando-se parâmetros urbanísticos que demonstrem novos modelos espaciais.

Para este fim utiliza-se o programa ENVI-MET, programa gratuito, que simula as interações entre as superfícies urbanas, vegetação e atmosfera. Para estas simulações são utilizados recortes urbanos representativos dos polígonos com áreas com aproximadamente $500 \mathrm{~m} \times 500 \mathrm{~m}$, conforme apresentado anteriormente. Esta especificação do tamanho da área foi baseada em estudos já realizados com o referido programa. Este programa computacional utiliza modelos de simulação dos fluxos de ar, turbulências, perfis de temperatura e umidade e fluxos de radiação, que ocorrem entre a atmosfera e as superfícies próximas ao solo. Os dados de saída do programa, na forma de mapas ou gráficos, facilitam ao usuário analisar a interação entre os parâmetros físicos do ambiente construído com o microclima. Dessa forma, o programa constitui uma ferramenta no processo de desenho urbano, sendo útil na comparação de cenários que contemplam variações na morfologia, tipologia e densidade construtivas, permeabilidade do solo e índice de vegetação.

Assim, nesta etapa, com o objetivo de gerar recomendações para o planejamento urbano, através da sobreposição de dados ambientais com a estrutura urbana, serão elaborados os modelos interativos, como ferramenta de auxílio ao planejamento urbano e projeto, enriquecidos pelo suporte de tecnologias provenientes do desenho assistido por computador, pelo sistema de informação geográfica e pela realidade virtual. Utilizamse tanto o geoprocessamento como ferramenta de análise e suporte a avaliação do ambiente térmico urbano como a simulação computacional.

\section{CONCLUSÕES}

Acredita-se que a construção de um método não termina com a sua elaboração intelectual, mesmo quando é fruto da experiência empírica de pesquisas anteriores. Portanto, o presente artigo abre a possibilidade de uma contínua construção do método adotado pelo grupo. Trata-se de uma estratégia onde os procedimentos que compõem o método deverão ser revistos a cada novo conceito apreendido pelo grupo e a cada contexto que aponte para questões até então não abordadas.

A troca de experiências resulta em maior abrangência dos estudos, no aprimoramento metodológico e na possibilidade de realização de cenários futuros, visando à adaptação dos espaços urbanos e periurbanos a mudanças climáticas. A discussão teve como objeto a adaptação de cidades às mudanças climáticas em curso, com foco 
na relação entre indicadores climáticos selecionados e parâmetros, físico ambiental e socioambiental, entre os quais os urbanísticos, aplicáveis no planejamento e projetos urbanos. $\bigcirc$ foco das análises físico ambientais é o ciclo das águas em áreas de cobertura de solo urbano e florestal, não incluindo análises químicas e bioquímicas. Os resultados são baseados em estudos teóricos e empíricos sobre a influência dos diferentes usos e tipos de morfologia urbana, a qualidade da cobertura vegetal e dos ecossistemas em suportes físicos distintos (encostas, fundos de vale, baixadas) e o efeito climático nos ambientes rural, florestal e urbano, atuais e futuros, em áreas selecionadas nas regiões metropolitanas de Campinas (SP) e Rio de Janeiro (RJ).

Nesse contexto, que lida com integração de áreas do conhecimento e diferentes assuntos territoriais, a elaboração de simulações e cenários espacializados é um recurso fundamental para a pesquisa sobre a compreensão dos impactos negativos e positivos decorrentes de decisões de planejamento e projeto urbano. A exploração de modelos para os cenários da morfologia e crescimento urbanos auxilia o conhecimento sobre o futuro, possibilitando ao poder público o aprimoramento de políticas públicas, otimizando o ensino e a formação de profissionais ligados à produção do espaço urbano, na gestão pública ou privada.

\section{Agradecimentos}

Agradecemos à Fundação de Amparo à Pesquisa do Estado de São Paulo - FAPESP - e à Fundação Carlos Chagas Filho de Amparo à Pesquisa do Estado do Rio de Janeiro - FAPERJ, pelo apoio.

\section{Notas}

1 Projeto foi desenvolvido em parceria com a Pontifícia Universidade Católica de Campinas, SP, Universidade Federal do Rio de Janeiro e a Pontifícia Universidade Católica do Rio de Janeiro, e concorreu aos recursos FAPESP, dentro da Chamada de Propostas de Pesquisas nas áreas de Mudanças Climáticas Globais Convênio FAPESP-FAPERJ, e aos recursos da FAPERJ, dentro do Edital FAPERJ 23/2010, sendo exigências, da Chamada e do Edital, a participação de instituições dos dois estados. A equipe é composta pelos autores deste artigo. $\bigcirc$ projeto foi aprovado em setembro de 2011 e tem dois anos de duração.

\section{Bibliografia}

ABREU, J. R. S .P.; OLIVEIRA, R.R. e MONTEZUMA, R.C.M.. Dinâmica da serrapilheira em um trecho de floresta atlântica secundária em área urbana do Rio de Janeiro. Pesquisas Botânicas, n. 61, 2010. p. 279-291.

ANDRADE, H.. O clima urbano - Natureza, escalas de análise e aplicabilidade. In: FINISTERRA, XL, 80, 2005. p. 67-91.

BRUSE, M.; FLEER, H.. Simulating surface-plant-air interactions inside urban environments with a three dimensional numerical model. Environmental Modelling \& Software, 13, 1988. p.373-384.

BUENO, L. M. M.; CYMBALISTYA, R. (Orgs.). Planos diretores municipais: Novos instrumentos de planejamento territorial. São Paulo: AnnaBlume, 2007. 
; MARTINS, M. L. R.. Introdução - Caderno de Resumos do Seminário APPUrbana 2007. São Paulo: ANPUR/ANAMMA/ FAUUSP/FAU-PUC Campinas, 2007. CdRom e Papel.

; OLIVEIRA G. O.; ALMEIDA E. R.; ALMEIDA V. M.. Intervenção em favelas na perspectiva de uma regularização fundiária sustentável: Limites e avanços. In: V Encontro Nacional e III Encontro Latino Americano sobre Edificações e Comunidades Sustentáveis. Anais.... Recife, 2009.

O tratamento dos assentamentos urbanos na política para as mudanças climáticas. In: V Encontro da Associação Nacional de Pós Graduação e Pesquisa em Ambiente e Sociedade - ANPPAS. Anais... Florianópolis, 2010.

Reflexões sobre o futuro da sustentabilidade urbana a partir de um enfoque socioambiental. Cadernos Metrópole, São Paulo: PUC, v. 19 p. 99-122, 2008.

DACANAL, C.; PEZZUTO, C. C.; LABAKI, L. C.. Microclima em fundos de vale: Análise de diferentes ocupações urbanas em Campinas, SP In: XII Encontro Nacional de Tecnologia do Ambiente Construído e XII Encontro Nacional De Tecnologia Do Ambiente Construído. Anais... Fortaleza, 2008.

HUNT A.; WATKISS, P.. Climate change impacts and adaptation in cities: A review of the literature. Climate Change. DOI 10.1007/s10584-010-9975-6, Dezembro, 2010

MONTEZUMA, R. C. M.; SESANA, E.G.. Conectando cidades e florestas: O caso do município de Nova Iguaçu. In VI Seminário Latino Americano e II Seminário Ibero Americano de Geografia Física, Anais... Coimbra, 2010.

; FIALHO, E. S.; IMBROISI, E. G.. O papel da serrapilheira como agente regulador de fatores físicos

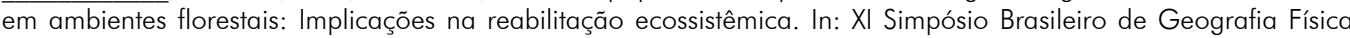
Aplicada. Anais.... São Paulo: USP, 2005b.

Produção e reabilitação funcional do piso florestal de cicatriz de deslizamento/PNt, Rio de Janeiro. Tese (Doutorado) - IGEO/CCMN/UFRJ. Rio de Janeiro, 2005a. 294p.

; OLIVEIRA, R. R.. Os ecossistemas da Baixada de Jacarepaguá e o PEU das Vargens. Arquitextos, v. 3, artigo n. 116, 2010

NOBRE, C. et. al. Vulnerabilidade das megacidades brasileiras às mudanças climáticas: A região metropolitana de São Paulo. Junho de 2010. Disponível em http://www.inpe.br/noticias/arquivos/pdf/megacidades.pdf

OLIVEIRA G. O.; BUENO L. M. M.. Assentamentos precários em áreas ambientalmente sensíveis. Arquitextos, v. 16, artigo n. 114, 2009.

PEZZUTO, C. C.; LABAKI, L. C.; FRANCISCO FILHO, L. L.. Influence of land use and occupation in the urban heat island. In: PLEA - 25 th Passive and Low Energy Architecture International Conference. Dublin, 2008.

Avaliação do ambiente térmico nos espaços urbanos abertos: Estudo de caso em Campinas, SP. Tese (Doutorado) - Faculdade de Engenharia Civil, Arquitetura e Urbanismo, Universidade de Campinas. Campinas, 2007

PINTO, V. C.. O Plano Diretor Brasileiro à Luz do Direito Comparado. In: FERNADES, Edesio e ALFONSIN, Betania. Direito Urbanístico: Estudos brasileiros e internacionais. Belo Horizonte: Del Rey, 2006.

REGO, A. Q.; SOUZA, J.; CARDEMAN, R. G.; SCHLEE,M. B.; DIAS, M. A. \& TANGARI, V. R.. The open spaces system in the Rio de Janeiro State in Brazil: The administrative frontiers shaping the territorial landscape. In: International Seminar on the Urban Form Conference Proceedings. Anais... ISUF: Guangzhou, 2009.

ROAF, S. et al. A adaptação de edificações e cidades às mudanças climáticas. Porto Alegre: Bookman, 2009.

SANTOS, A. H.; MONTEZUMA, R. C. M.; MARANHÃO, M. S.. A transformação da paisagem fluminense: Influência da orientação de encosta na funcionalidade ecológica do maciço da Pedra Branca/RJ. In: VIII Encontro Nacional da ANPEGE, 2009. Anais... Curitiba: Ponto4 Digital, 2009.

SILVA, J. M. P. da. Habitação de interesse social e as legislações municipais da região metropolitana de Campinas. In: Ambiente Construído, Porto Alegre, v. 11, n. 3, p. 55-71, jul./set. 2011.

Percepção e transformação da paisagem: Planejamento, apropriação e ações públicas na região metropolitana do Rio de Janeiro. In: TÂNGARI, MONTEZUMA, REGO e SOUZA. O arco metropolitano do Rio de Janeiro: Integração e fragmentação da paisagem e dos espaços livres de edificação. Rio de Janeiro: PROARQ-FAUUFRJ, 2010a. (no prelo)

How can tomorrow's cities become more socially equal if the current master plan does not correctly deal with the property's social function? In: 54IFHP - World Congress. Porto Alegre, 2010b.

O planejamento participativo e a transformação da paisagem: Planos diretores em onze municípios do Espírito Santo, um estudo de caso. In: TÂNGARI, Vera R.; Schlee Mônica B.; Andrade, Rubens de; DIAS, Maria Ângela 
(Org.). Águas urbanas: Uma contribuição para a regeneração ambiental como campo disciplinar integrado. Rio de Janeiro: FAU-UFRJ-PROARQ, 2007, p.173-214.

TÂNGARI, V. R.; DIAS, M. A.; AMORIM, F. P.. Projeto do Parque da Orla da llha do Fundão no Rio de Janeiro. In : BUENO, L.; MARTINS, M. L. R. (Org.). Anais do APPUrbana 2007. São Paulo: ANPUR/ANAMMA/ FAUUSP/FAUPUC Campinas, 2007. CdRom

; SCHLLE M. B.; Andrade, Rubens de; DIAS, Maria Ângela (Org.). Águas urbanas: Uma contribuição para a regeneração ambiental como campo disciplinar integrado. Rio de Janeiro: FAU-UFRJ-PROARQ, 2007.

. I Seminário Nacional sobre Regeneração Ambiental de Cidades - Águas Urbanas. Anais... Rio de Janeiro: FAU-UFRJ, 2005. CdRom.

ARQ, 2009.

Sistema de espaços livres: $\bigcirc$ cotidiano, apropriações e ausências. Rio de Janeiro: FAU-UFRJ-PRO- 